\title{
The Blood-vessels of the Middle Ear, in Relation to the Development of the Small Ear-bones and their Muscles.
}

(A preliminary report)

By

\section{Denjiro Nabeya.}

(From the Anatomical Department of the Kyoto Imperial University)

(Prof. B. Adachi).

With 2 Figures (Plate XXI).

Although we have had many investigators of the blood-vascular system of the internal ear, there has not, as yet, been one who has made a systematic study of the blood-vessels of the middle ear. Consequently, we are wanting in the knowledge of this subject. I have, therefore, undertaken the research of this subject, since I finished the work of the comparative study of the anatomy of the vascularization in the labyrinth, which will be taken up in a future report.

In the course of this present research of the middle ear, I discovered a very interesting and important fact as to the close relation between the bloodvascularization and the development of the small bones and their muscles in the midale ear.

I applied a new plan of mine to this work, which modified Spalteholz's method of rendering transparent anatomical preparations of the materials of embryos and adults of man. By means of this method, I found four arteries in two sets of two each ; the first set branches from $A$. meningea media, and second set branches from $A$. stylomastoidea âs follows :

A. meningea media (First set);

1) Arteria nutricia incudo-mallei.

2) ramus tensor tympani.

A. stylomastoidea (Second set);

1) Arteria stapedia, 
2) Arteria musculi stapedii.

The two arteries of the first set of the above, supply the interior substance of malleus, Incus, and their muscle, and the other two supply the stapes and its muscle.

The fact is known generally that these small bones and their muscles develop from two branchial arches (Reichert $)^{1)}$ and these bones and muscles are supplied by two different nerves respectively. The first branchial arch produces Malleus, Incus, and their muscle, namely, M. tensor tympani, which muscle is supplied by $N$. tensor tympani, a small branch of III. branch of $N$. trigeminus. The second branchial arch produces Stapes and its muscle, namely, $M$. stapedius; this muscle is supplied by $N$. stapedius which is a branch of $N$. facialis.

In other words, the product of the first branchial arch is controlled by III. branch of $N$. trigeminus while $N$. facialis has control of the product of the second branchial arch, in the middle ear.

In this relation, it must be called to mind that the same relation holds true in the blood-vascular syste malso. Gaupp actually put forword this supposition in his work. I have, however, not found any one who has studied this interesting subject exhaustively or given further testimony.

I believe that the four arteries of the above are sufficient to substantiate this supposition, because these arteries have just the same relation as the nervous system of the small bones and their muscles in the following distributed condition :

1) A. nutricia incudo-mallei arises from A. meningea media on the entering the cranium passed through Foramen spinosum and runs along the out wall of the Semicanalis tensor tympani giving off some branches on $\boldsymbol{M}$. tensor tympani; and then it enters Recessus epitympanicum and penetrates into Malleus and Incus by its two terminal branches respectively which supply their interior substance by many radiating capillaries.-The situation of the aperture for the passage of this nutrient artery of the small bones is : at the neck of Malleus, and in Incus, at the root of its long process120.

1) Archiv für Anatomie, Physiologie und Wissenschaftliche Medicin, Jahrgang 1837, s.

2) Archiv für Anatomie, Physiologie; Anatomie Abteilung mit Supplement, Jahrgang 1912 , s. 390. 
2) Ramus tensor tympani is a fine branch which arises directly from the trunk of $A$. meningea media or indirectly from a branch of it and supplies $\mathbf{M}$. tensor tympani.

In short, these two are branches of A. meningea media and this mother artery has a close relation with III. branch of $\mathrm{N}$. trigeminus.

3) A. stapedia arises from $A$. stylomastoidea and passes into the two crura of Stapes supplying their vicinity.

4) A. musculi stapedii is a branch of $A$. stylomastoidea and supplies M. stapedius and its vicinity.

In short, these two are branches of $A$. stylomastoidea, and this mother artery runs along the inside of the facial canal with $N$. facialis.

The existence of the latter two, i. e., the branches of $A$. stylomastoidea was made sure by the description of $\mathrm{Z} \mathrm{u} \mathrm{ckelkand1^{1) }}$ also, the former two, i. e., the branches of $A$. meningea media which are found in this research, are an entirety new system of the blood-vessels of the ruiddle ear and can not be found in any preceeding literature as far as a description of this system is concerned.

The foregoing facts establish the proposition that the blood-vascular system has two different areas, just, as does the nervous system, is in two distinct areas developing from the first and second branchial arches.

I made the following table to clearly explain this conclusion :

\begin{tabular}{|c|c|c|}
\hline$\cdot$ & First branchial arch & Second branchial arch \\
\hline Bone & $\begin{array}{l}\text { Malleus } \\
\text { Incus }\end{array}$ & Stapes \\
\hline Muscle & M. tensor tympani & M. stapedius \\
\hline Nerve & $\begin{array}{l}\text { III. branch of N. trigeminus } \\
\text { N. tensor tympani }\end{array}$ & $\begin{array}{l}\text { N. facialis } \\
\qquad \text { N. stapedia }\end{array}$ \\
\hline Artery & $\begin{array}{l}\text { A. meningea media : } \\
\text { A. nutricia incudo-mallei } \\
\text { R. tensor tympani }\end{array}$ & $\begin{array}{l}\text { A. stylomastoidea': } \\
\text { A. stapedia } \\
\text { A. musculi stapedii }\end{array}$ \\
\hline
\end{tabular}

In this short statement, I believe I have made a contribution to the interesting problem of the morphology of the middle ear.

1) Monatsschlift für Ohrenheilkunde, Jahrgang 1873, p. 273. 
Fig. 1-A. nutricia incudo-mallei and R. tensor tympani in area of third branch of $\mathrm{N}$. trigeminus. (Semi-Schematic, left ear).

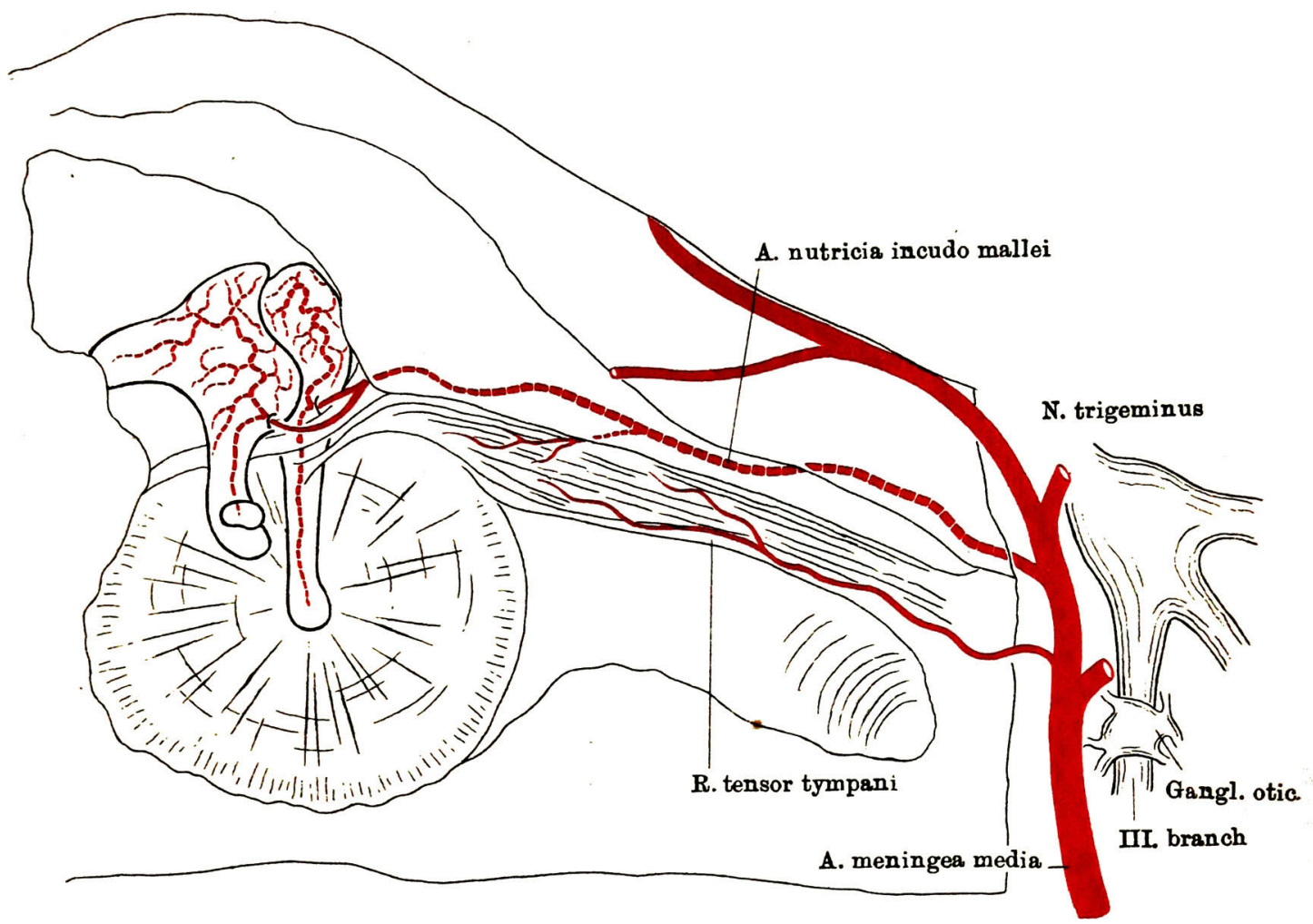

Fig. 2-A. stapedia and A. musculi stapedii in area of N. facialis (left ear).

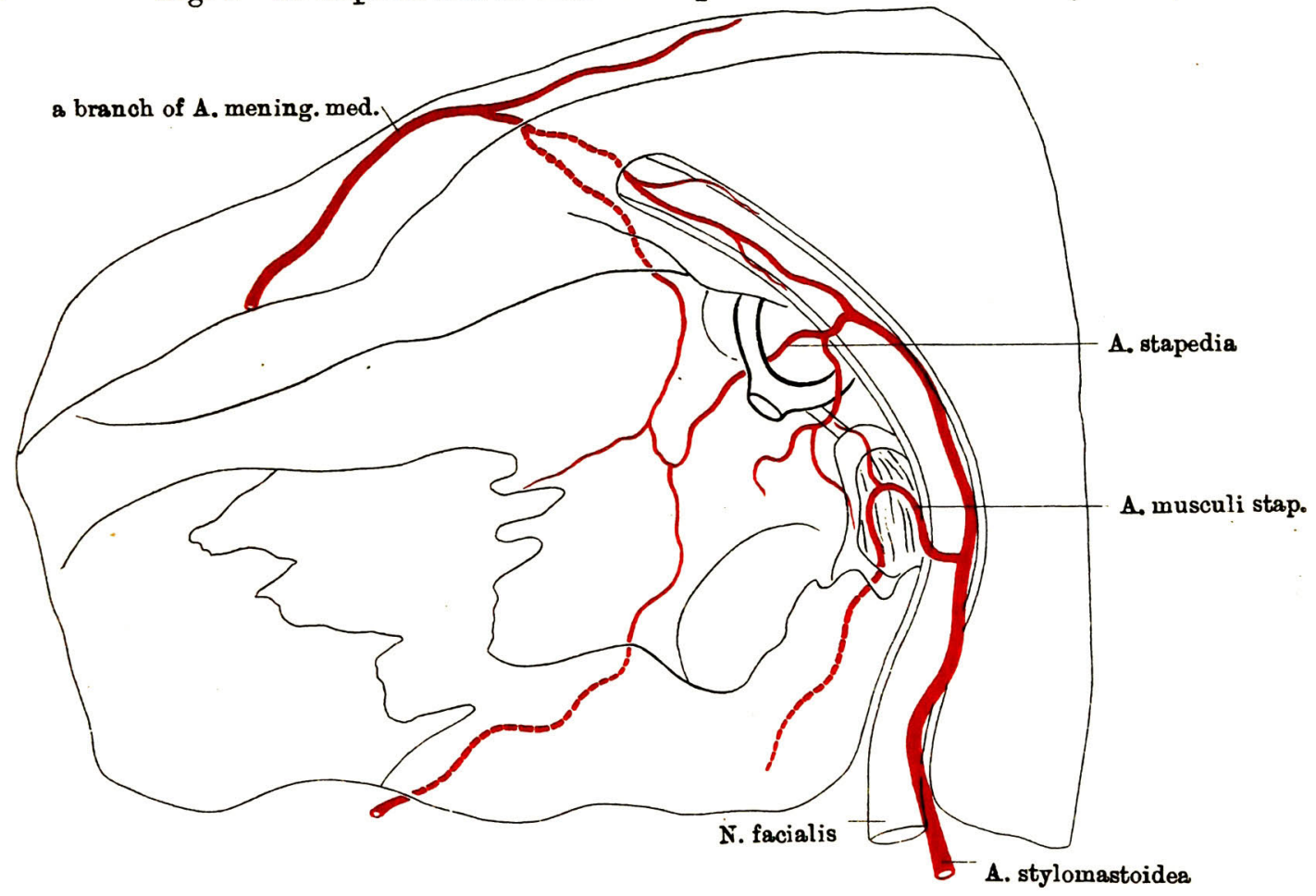

The blood-vessels of the middle ear. Denjiro Nabeya 